\title{
Processos Pedagógicos Escolares e Afrocentricidade: um Estudo de Caso
}

\author{
HORA FILHO, Edmilton Amaro da ${ }^{1}$ \\ NASCIMENTO, Irene Késsia das Mercês \\ MESSIAS, Edmilsa Josefa de Santana ${ }^{3}$
}

\section{RESUMO}

A presente investigação tem como foco verificar os processos pedagógicos escolares como fortalecimento da afrocentricidade no combate ao racismo no ambiente escolar. Considerando histórias de racismo discriminação e preconceitos no ambiente escolar. Tendo como base as orientações propostas pela lei 10.639/03 e as Diretrizes Curriculares Nacionais para Educação das Relações Étnico Raciais de 2004. O objetivo Geral dessa pesquisa está em investigar o Projeto "O Baobá, Árvore que Representa as Raízes da Cultura Africana" realizado na a Escola Municipal Albenice Maria da Silva, Jaboatão dos Guararapes - PE. O projeto compôs o Fórum Escolar de Consciência Negra, que foi realizado na instituição de ensino no ano de 2019. Para fundamentação teórica nos aproximamos os estudos da teoria da afrocentricidade. Como metodologia a análise do conteúdo dos objetivos do projeto entendendo que estes puderam nos mostrar processos pedagógicos que se voltavam e/ou se afastavam de uma perspectiva de educação afrocentrada. Nesse estudo de caso identificamos os esforços para a sensibilização de estudantes acerca dos valores humanos e de processos pedagógicos que ultrapassem as fronteiras do racismo, da discriminação e da violência dentro e fora dos muros da escola.

Afrocentricidade. Processos Pedagógicos. Baobá.

School Pedagogical Processes and Afrocentricity: A Case Study

\footnotetext{
1 Doutorando em EDUCAÇÃO pela (UFPE). Mestre em Educação pela (UFPE). Email: pretohora@hotmail.com. Lattes: http://lattes.cnpq.br/4933465694751176. Orcid: https://orcid.org/0000-0001-7586-7643.

2 Mestrando em Educação na linha de Pesquisa de Teoria e História da Educação pela (UFPE). Especialista em Psicopedagogia Clínica e Institucional - Faculdade Alfamerica. Email: irene_kessia@hotmail.com. Lattes: http://lattes.cnpq.br/5811554817283949. Orcid: https://orcid.org/0000-0002-8694-2052.

3 Especialista Prefeitura Municipal de Jaboatão dos Guararapes. Email: edmilsamessias4175@gmail.com. Lattes: http://lattes.cnpq.br/9242408671475757. Orcid: https://orcid.org/0000-0001-6616-8912.
}

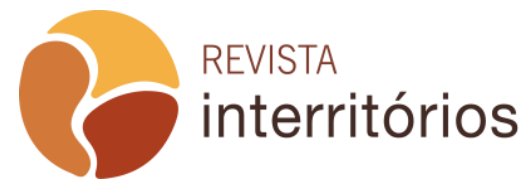




\section{ABSTRACT}

The present investigation focuses on verifying school pedagogical processes such as strengthening Afrocentricity in the fight against racism in the school environment. Considering stories of racism, discrimination and prejudice in the school environment. Based on the guidelines proposed by law 10.639 / 03 and the National Curriculum Guidelines for the Education of Ethnic Racial Relations of 2004. The general objective of this research is to investigate the Project "O BAOBÁ, TREE THAT REPRESENTS THE ROOTS OF AFRICAN CULTURE" held at the Municipal School Albenice Maria da Silva, Jaboatão dos Guararapes - PE. The project was part of the SCHOOL FORUM OF COSNCIÊNCIA NEGRA, which was held at the educational institution in 2019. For theoretical foundation we approached the studies of the theory of Afrocentricity. As a methodology, the analysis of the content of the project's objectives, understanding that they could show us pedagogical processes that turned and / or moved away from an Afro-centered education perspective. In this case study, we identified efforts to raise students' awareness of human values and pedagogical processes that go beyond the boundaries of racism, discrimination and violence inside and outside the school walls.

Afrocentricity. Pedagogical Processes. Baobab.

\section{Procesos pedagógicos escolares y afrocentricidad: un estudio de caso}

\section{RESUMEN}

La presente investigación tiene el objetivo de verificar los procesos pedagógicos escolares como fortalecimiento de la afrocentricidad en la lucha contra el racismo en el ámbito escolar. Considerando historias de racismo, discriminación y prejuicios en el entorno escolar. Con base en los lineamientos propuestos por la ley 10.639 / 03 y las "Diretrizes Curriculares Nacionais para Educação das Relações Étnico Raciais" de 2004. El objetivo general de esta investigación es investigar el Proyecto "O BAOBÁ, ÁRVORE QUE REPRESENTA AS RAÍZES DA CULTURA AFRICANA" realizado en la Escuela Municipal Albenice Maria da Silva, Jaboatão dos Guararapes - PE. El proyecto formó parte del "FÓRUM ESCOLAR DE CONSCIÊNCIA NEGRA", que se realizó en la institución educativa en el año 2019. Para fundamentación teórica nos acercamos a los estudios de la teoría de la afrocentricidad. Como metodología, el análisis del contenido de los objetivos del proyecto, entendiendo que pudieron mostrarnos procesos pedagógicos que se acercaban y/o se alejaban de una perspectiva de educación afrocentrada. En este estudio de caso, identificamos esfuerzos para sensibilizar a los estudiantes sobre los valores humanos y los procesos pedagógicos que van más allá de los límites del racismo, la discriminación y la violencia dentro y fuera de las paredes de la escuela. 
Afrocentricidad. Procesos pedagógicos. Baobá

\section{Processi pedagogici scolastici e afrocentricità: un caso di studio}

\section{SOMMARIO}

La presente ricerca ha l'obiettivo di verificare i processi pedagogici scolastici come rafforzamento dell'Afrocentricità nella lotta al razzismo in ambito scolastico. Considerando storie di razzismo, discriminazione e pregiudizio nell'ambiente scolastico. Sulla base delle linee guida proposte dalla legge 10.639 / 03 e delle "National Curricular Guidelines for Education for Ethnic Relationships Raciais" del 2004. L'obiettivo generale di questa ricerca è indagare il Progetto "O BAOBÁ, ÁRVORE CHE RAPPRESENTA COME RAÍZES DA CULTURA AFRICANA "Presso la scuola municipale di Albenice Maria da Silva, Jaboatão dos Guararapes - PE. II progetto faceva parte del "FORUM ESCOLAR DE CONSCIÊNCIA NEGRA", che si è tenuto presso l'istituto scolastico nel 2019. Per giustificazione teorica ci avviciniamo agli studi della teoria dell'afrocentricità. Come metodologia, l'analisi del contenuto degli obiettivi del progetto, comprendendo che potevano mostrarci processi pedagogici che si stavano avvicinando e / o allontanandosi da una prospettiva educativa afro-centrata. In questo caso di studio, identifichiamo gli sforzi per sensibilizzare gli studenti ai valori umani e ai processi pedagogici che vanno oltre i confini del razzismo, della discriminazione e della violenza dentro e fuori le mura della scuola.

\section{Afrocentricità. Processi pedagogici. Baoba.}

\section{INTRODUÇÃO}

O Presente estudo está direcionado aos processos pedagógicos de fortalecimento da afrocentricidade no combate ao racismo em sala de aula. $O$ motivo que nos levou a realizar esta investigação foi o combate ao racismo, que pode ocorrer dentro de sala de aula, bem como a afirmação dos valores culturais de matrizes africanas e afro-brasileiras.

Ressaltamos nessa discussão a necessidade de aprendizagem dos saberes afrocentrados, uma vez que percebemos na sociedade brasileira a necessidade de combate à discriminação, ao preconceito e ao racismo antinegro, que é fruto de um histórico de ausência de práticas escolares que levem em consideração a pluralidade étnica brasileira e da não consideração de que - Brasil, de acordo com o IBGE (2000), possui $47 \%$ de negros em sua população e que em Pernambuco, $58,2 \%$ de negros, portanto, os estudantes no público assistido pela unidade de ensino, em sua maioria absoluta, pertencem à etnia afrodescendente. 
No Brasil, a implementação da lei federal 10.639 em 2003, alterada pela lei 11.645 em 2008, que descrevem que as escolas públicas e particulares de todos os níveis e modalidades de ensino a ensinar a História e a Cultura Afrobrasileira e Africana, seguindo através das orientações das Diretrizes Curriculares Nacionais para a Educação das Relações Étnico raciais de 2004, que nos propõe, aos educadores/às, trabalhar no sentido da prática de três importantes princípios: Consciência Histórica e Política da Diversidade, Fortalecimento das Identidades e dos Direitos e Práticas Educativas de Combate ao Racismo e às Discriminações, corroborando nos espaços educativos, a conscientização da contribuição da população negra dentro da sociedade.

Para que se possa vencer os casos de racismo dentro dos espaços educativos é necessário que se tenha a consciência do mal que o racismo pode causar nas vidas das pessoas deixando sequelas, ainda dificultando $o$ processo escolar dos alunos. Assim, justificando a presente investigação, além da lei acima citada, temos a opinião de que para o enfrentamento é preciso ressaltar a contribuição do negro no Brasil. Conferindo assim, um olhar a partir da centralidade do discurso afro na sociedade com vistas à uma promoção da igualdade e diminuição dos racismos. Diante dessas problemáticas abordadas acima que refletimos sobre a questão central desse estudo de caso: Como $o$ fórum escolar de consciência negra dialoga com os princípios da afrocentricidade?

Sabe-se que valores africanos e afro-brasileiros estão sendo transmitidos através de ensinamentos que podem ser refletidos a partir da afrocentricidade. $O$ foco desse trabalho está em analisar o fórum escolar em seus objetivos, que foram alicerçados no Baobá, árvore símbolo fundamental para algumas culturas africanas, por ser uma árvore ancestral. Sendo o Baobá, o tema gerador. Como essa representação pode empoderar os alunos/as e professores/as através dos processos pedagógicos da escola numa prespectiva afrocentrada? Assim, investigamos o Projeto "O Baobá, Árvore que Representa as Raízes da Cultura Africana" realizado na a Escola Municipal Albenice Maria da Silva, que fica localizada no endereço Rua Vitória Régia, 744 - Dois Carneiros, Jaboatão dos Guararapes - PE, 54270-060. O projeto compõe o Fórum Escolar de Consciência Negra, que foi realizado na instituição de ensino no ano de 2019.

\section{A escola e o projeto}

Observando a escola como um grande jardim o principal cultivo será o próprio conhecimento "O conhecimento é como um jardim: se não for cultivado, não pode ser colhido!" (Provérbio africano). Antes de tratar do tema em questão é necessário situar a localização e características principais do campo de estudo e o projeto que foi 
desenvolvido. Quanto a caracterização da Escola e do projeto podemos dizer que a Escola Municipal Albenice Maria da Silva, que fica localizada no endereço Rua Vitória Régia, 744 - Dois Carneiros, Jaboatão dos Guararapes - PE, 54270-060. O público de atenção da instituição de ensino aqui pesquisada incluímos crianças e adolescentes. Dividido em anos, que vão do 6 ao 9a ano e as idades vão de 11 a 14 anos, cronologicamente um ano para cada série. Vale ressaltar que em algumas séries são incluídos alunos que se encontram fora dessa faixa chegando a um extremo de 17 anos no máximo, porém, estes são uma minoria. No bairro de Dois Carneiros, Jaboatão dos Guararapes, existem mais mulheres do que homens. Sendo a população composta de $51.49 \%$ de mulheres e $48.51 \%$ de homens IBGE (2010). Total que se reflete também na Escola, sendo assim, o total de alunas é maior que o de alunos matriculados. Os matriculados são do próprio bairro e também de comunidades adjacentes, vale ressaltar que o bairro de Dois Carneiros em Jaboatão-PE faz limite com os bairros de Santana, Sucupira, Socorro, Pacheco em Jaboatão-PE e os bairros do Barro e Cohab em Recife-PE. Dentre os quais prevalecendo no número total de matrículas alunos e alunas do próprio bairro.

Em se falando de Estrutura da Escola, abordamos os Elementos físicos (espaço, instalações, materiais) e organizacionais. Quanto à estrutura física podemos falar em uma escola de grande porte e com dois blocos de área construída não arborizada e com uma grande quadra poliesportiva. As instalações são bem satisfatórias com salas de aula, uma área de convivência coberta e banheiros. A disponibilidade de materiais está acima do padrão das escolas municipais da região, que infelizmente ainda não seriam o "ideal" para um trabalho educacional plenamente contemplado. $\mathrm{Na}$ Estrutura organizacional a Escola conta com o ensino fundamental II distribuídas nos horários da manhã e tarde.

Quanto ao projeto, ressaltando a necessidade de aprendizagem dos saberes afrodescendentes, uma vez que percebe-se na sociedade brasileira, na comunidade local e na escola, a necessidade de combate à discriminação, ao preconceito e ao racismo antinegro, que é fruto de um histórico de ausência de práticas escolares que levem em consideração a pluralidade étnica brasileira. Considerando o fato de que os estudantes no público assistido pela unidade de ensino, em sua maioria absoluta, pertencem à etnia afrodescendente. Entende-se que,

É necessário o conhecimento de outras culturas, outras realidades, mas sobretudo é essencial que o educando conheça e valorize a sua própria cultura para que possa valorizar a sua realidade notando que o seu contexto faz parte de sua história, bem como de sua formação. (SANTOS \& RODRIGUES, 2019, p. 258)

A realização de um FÓRUM ESCOLAR DE COSNCIÊNCIA NEGRA começou na escola no ano de 2017. Desde a primeira edição, conta com 
edições anuais com a participação de alunos e professores oferecendo a oportunidade de desenvolver uma cultura antirracista, bem como, demonstrar o poder educativo da cultura afro com esforços interdisciplinares focando em práticas e ideais de uma sociedade diversa e igualitária. Fomentando também experiências concretas de pesquisa. Ainda, reforça-se a visibilidade na comunidade que a escola está inserida e no Estado, constituindo um evento social que conta com a presença de pais, autoridades políticas e comunidade interessada trazendo uma maior visibilidade para as experiências exitosas da educação no município de Jaboatão-PE. O fórum escolar busca fomentar o conhecimento necessário e adequado para aplicação a Lei 10639/03 dentro de uma sala de aula, assim compreendendo o êxito do trabalho, foi incorporado ao Projeto Político da Escola (PPP). Considerando também, que a escola está no chão de uma comunidade que tem sua população em grande parte formada por afrodescendentes e afro-brasileiros oriundos dos antigos escravizados do Engenho Santana, que é localizado próximo a escola, o projeto permanente no PPP da escola se funda no propósito de elevar a autoestima dessa comunidade. A inclusão do projeto no PPP da escola foi feita sob o regime democrático do ensino público, porquanto contou com a participação da comunidade escolar a partir das suas considerações sobre a função social da escola e a realidade em que a mesma está inserida, investigando caminhos para as aspirações desta comunidade.

O FÓRUM ESCOLAR DE CONSCIÊNCIA NEGRA é desenvolvido no mês da consciência negra, que é utilizado pela sociedade brasileira para o reconhecimento e reflexão acerca da importância e da valorização da cultura africana no país. Assim sendo, a escola decidiu que trabalhar a consciência negra requer um tempo maior, muito mais que o dia 20 de novembro, por isso, a Escola Municipal Albenice Maria da Silva tem dedicado parte do ano letivo para debates e reflexões sobre educação das relações étnico-raciais e a importância de cada grupo étnico no processo de construção de nosso país, estado e comunidade. De modo mais específico a escola trabalhou no ano de 2019 na terceira semana do mês de novembro o fórum(figura 01), que trouxe como tema: "O Baobá, Árvore que Representa as Raízes da Cultura Africana". 
Figura 01. Alunos na culminância do fórum

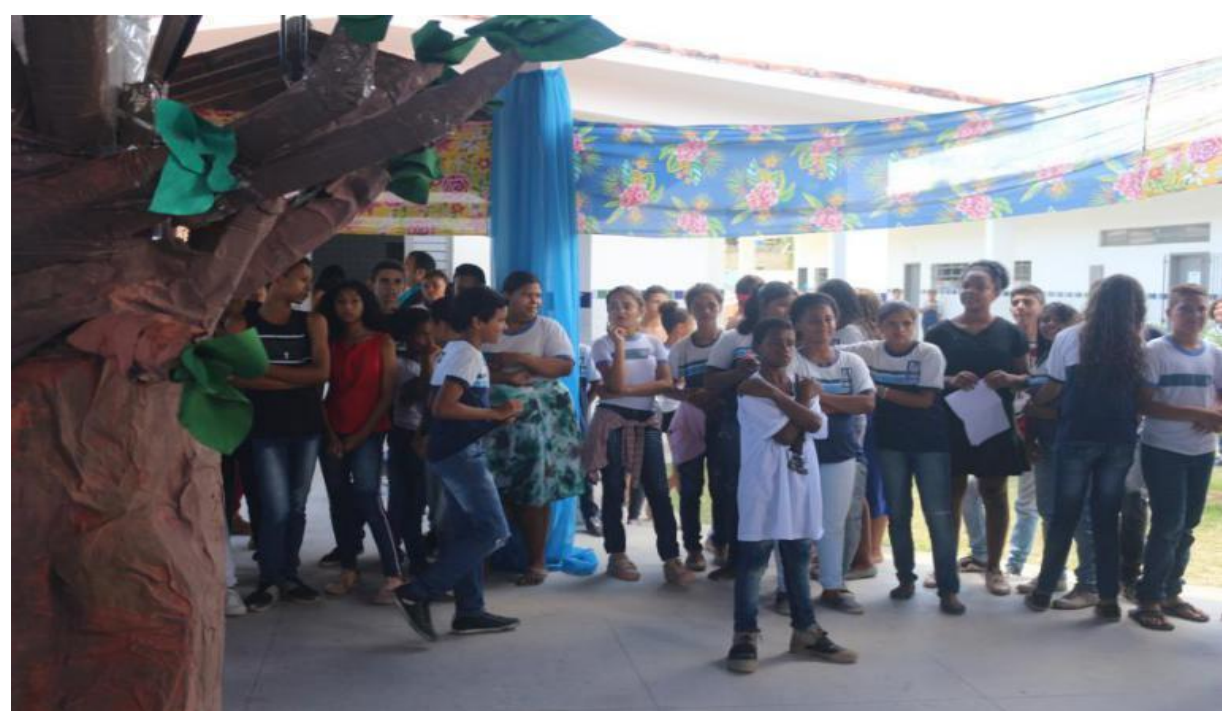

Fonte: Evandro da Hora (2019).

Nesse período, foram aplicadas atividades relevantes, que tiveram por objetivo além de conhecer com mais propriedade o legado cultural, histórico geográfico, artístico e religioso dessa árvore milenar, também minimizar todo o tipo de racismo, no chão da escola, propiciando a criação de espaços para manifestações artísticas/educativas que proporcionaram momentos de reflexão crítica da realidade e afirmação positiva dos valores culturais afro pertencentes a sociedade. Esperavam com o fórum que os estudantes se sensibilizassem acerca dos valores humanos e que o projeto ultrapassasse as fronteiras que geram o racismo, a discriminação e a violência dentro e fora dos muros da escola. O tempo de execução foi de uma semana, entre 11 a 20 de novembro de 2019. O público alvo foi os alunos do anos finais do fundamental, bem como professores e comunidade. A culminância foi no dia 20 de novembro. O projeto teve uma característica interdisciplinar, envolvendo História, Língua Portuguesa, Geografia, Matemática, Ciências, Artes, Inglês, Educação Física.

Os professores foram incentivados a desenvolver atividades que, tendo - Baobá como tema gerador, buscassem em cada disciplina do currículo as possibilidades de ter o contato com a cultura afro aprendendo e produzindo. Desta forma surgiram a partir das proposições do corpo docente as seguintes atividades: Plantio de uma muda de Baobá; Confecção de mapas (Continente Africano); Cartazes mostrando os principais báobas do mundo; Apresentação de plantas medicinais africanas que incorporamos na cultura brasileira, ex. a Arruda, Ruta Graveolens, entre outras.

Além disso, apresentação de gráficos mostrando dados estatísticos (porcentagem) relacionados a quantidade de baobás no Nordeste; Criação de mural valorizando aspectos culturais; Biografia de algumas personalidades 
negras que se destacam na música, futebol, literatura, política, etc.; Apresentações artísticas envolvendo a cultura africana incorporada a brasileira; Acrósticos envolvendo palavras como: negro, africano, afrodescendente, cultura, etc.; Apresentação da culinária e ou alimentos africana introduzidos no Brasil (azeite-de-dendê, quiabo, vatapá, etc).; Desenhos relativos a vídeos ou contação de histórias relacionados ao tema "Consciência Negra: Educação sem Preconceito"; Músicas ou parodias que abordem a sociedade e o preconceito $(O$ preto em movimento, Olhos Coloridos, Etnia, Racismo é burrice, etc.); Leitura de contos, poemas com temas e autores afro-brasileiros; Exposição de textos de autores negros da literatura brasileira e africana (Castro Alves, Solano Trindade, etc.);Apresentações de pesquisas sobre os vocábulos trazidos pelos africanos e utilizados pelos brasileiros (tanga, abada, samba, tamanco, mocotó,etc.); Construção de um Glossário Uorubás; Palestra com um representante afrodescendente sobre "A Consciência Negra e o Preconceito com a mulher negra"; Apresentação de vídeos de documentários sobre a identidade, religiosidade, arte e beleza africana; Desfile mostrando a beleza da mulher e do homem negro; Apresentação de DVDs de histórias infantis, como: Menina bonita do laço de fita, bichos da África, Doce princesa negra, Ifá, o Advinho etc.; Apresentação danças, como: coco, capoeira, maracatu, axé etc.; Apresentações de paródias, músicas, e danças; Atividades de colagens sobre as brincadeiras dos negros; Construção de panfletos educativos sobre a valorização da cultura negra.

O objetivo geral do fórum escolar foi o de valorizar a cultura afrodescendente presente na Brasil, bem como seus costumes, valores, lutas e ensinamentos transmitidos a sociedade tendo como alicerce o BAOBÁ, árvore símbolo fundamental das culturas Africanas. Tendo também os objetivos específicos seguintes: Reconhecer a importância e a contribuição da cultura africana como fonte de conhecimento e aprendizagem que perpassaram a formação da cultura brasileira; Valorizar a cultura negra e seus afrodescendentes e afro-brasileiros, na escola e na sociedade; Valorizar a identidade do(a) adolescente negro(a); Desmitificar o preconceito relativo aos costumes religiosos provindos da cultura africana; Realizar discussões provocantes, por meio das rodas de conversa, sobre o preconceito sofrido pelos afrodescendentes em nossa sociedade, para um posicionamento mais crítico frente à realidade social em que vivemos; Refletir sobre o legado da cultura negra através da música, da alimentação, dos usos e costumes; Reconhecer a história, lendas e crendices religiosas em torno do Baobá, bem como sua importância cultural para os africanos e seu descendentes; Oportunizar, através do resgate cultural e apresentações artísticas, aos participantes o estímulo à pesquisa.

Nesta comunidade da escola não estão presentes de forma representativa manifestações culturais que ressaltem a negritude. Desta 
forma, podemos dizer que grande parte da comunidade do bairro não conhecia, até então, o Baobá. Assim, a começar pelo plantio de uma muda de um Baobá (figura 02) o ambiente escolar dialoga com o entorno da escola na oportunidade de ter um bem de um valor sociocultural inestimável. Ressaltamos que, os Baobás em Pernambuco são considerados um patrimônio político, cultural e social. A intensão é que de acordo com a árvore crescendo dentro do espaço da escola todas as pessoas que estiveram e fizeram parte desse processo estejam de certa forma conectadas. Pois, a árvore que foi plantada vai demorar mais de 80 anos para chegar a fase adulta e colocar frutos. Os alunos abraçaram o cuidado com a árvore e o que se espera é que mesmo depois de adultos o Baobá ainda estará lá como um marco na consciência e na memória afetiva de cada um afirmando o valor da cultura afro nas suas vidas. Além disso, os pais de alunos que estavam presentes conheceram o Baobá e a sua representatividade para o povo negro. O plantio foi sacralizado a partir e um rito de matriz africana. Para o envolvimento dos alunos foram instituídos entre os alunos os Guardiões do Baobá.

Figura 02. Plantio do Baobá.

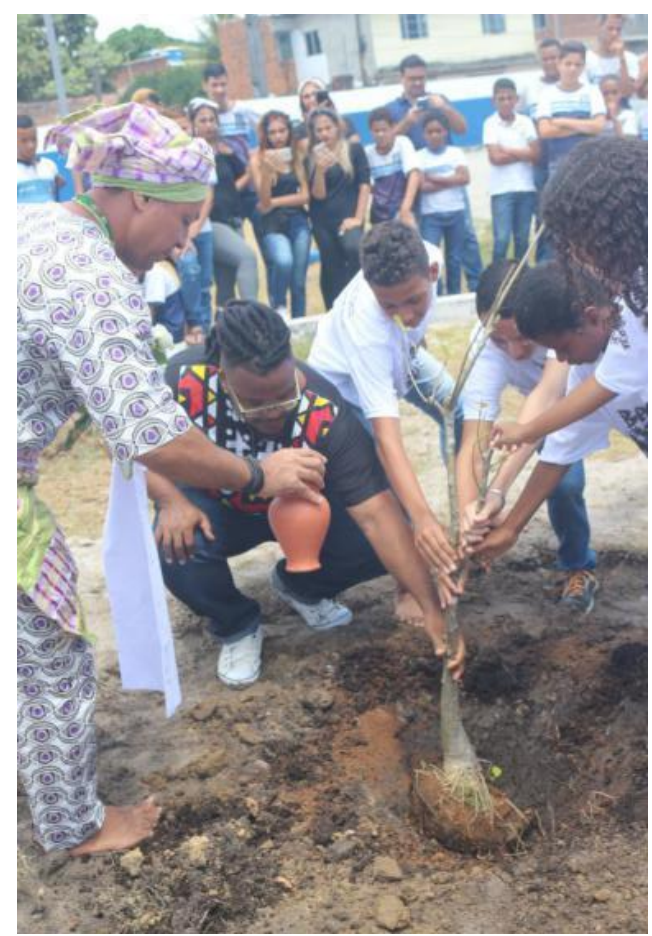

Fonte: Evandro da Hora (2019).

Estes alunos foram selecionados pela equipe de professores. $O$ intuito da ação foi o de estimular a responsabilidade do cuidado com a árvore para que a muda fosse regada todos os dias. A realização da culminância do Projeto 
contou com a participação dos pais e responsáveis. A intenção foi que o processo de problematização da consciência negra ultrapassasse os muros da escola.

Como essa teoria pode ser utilizada como um paradigma que desenvolva uma análise dos processos educativos? Consideramos as atividades e os processos pedagógicos desenvolvidos no fórum, que trouxe como tema: "O BAOBÁ, ÁRVORE QUE REPRESENTA AS RAÍZES DA CULTURA AFRICANA". Sabendo que, afrocentricidade engloba o pensar, as práticas e as perspectivas que colocam os africanos como sujeitos e agentes de fenômenos que versem sobre sua imagem cultural respeitando seus interesses humanos (ASANTE, 2009).

Aqui consideramos a afrocentricidade e seus princípios como uma proposição para enfrentamento ao racismo na escola. Quando falamos em afrocentricidade, falamos de uma teoria que se formalizou como paradigma teórico com a preocupação em ser imperativo frente às práticas eurocêntrista dos Estados Unidos da América e da Europa. A afrocentricidade se destacou entre os intelectuais negros/as, como uma teoria acadêmica. Esta teoria fortalece a cultura negra, centralizando a África em suas ações, sendo a mesma idealizada pelo professor Molefet Kate Assante ${ }^{4}$.

A afrocentricidade apresenta conceitos que fortalecem a teoria sendo eles: Localização, Conscientização, Agente e Agência.

A localização está relacionada como sujeito está localizado em relação as suas origens relacionadas a cultura africana e afro-brasileira. Pois segundo Asante (2009):

Localização", no sentido afrocêntricos, refere-se ao lugar psicológico, cultural, histórico ou individual ocupado por uma pessoa em dado momento da história. Assim, estar em uma localização é estar ficando temporária ou permanente, em determinado espaço. (ASANTE et al, 2009, p.95).

Ou seja, quando uma pessoa se localiza de maneira afrocêntrica se encontra em seu lugar psicológico, cultural, histórico ou individual de uma pessoa em um dado momento da história. Essa localização a leva a uma reflexão acerca de suas origens.

A teoria da afrocentricidade surgiu como um processo de conscientização de um povo que estava a margem da sociedade com suas

\footnotetext{
${ }^{4}$ Doutor em comunicação social, professor titular do Departamento de Estudos Afroamericanos da Universidade de Temple, Filadélfia, EUA. Sistematizou o paradigma da afrocentricidade em 1980.
} 
mentes enganadas pelo eurocentrismo. Um dos objetivos da teoria está em recentralizar os povos negros/as marginalizados/as e enganados/as pelo eurocentrismo, com a centralização dos sujeitos/as para afrocentricidade se abriria uma nova realidade de libertação das mentes dos povos africanos. Vejamos abaixo:

A ideia de conscientização está no centro da afrocentricidade por ser o que a tornar diferente da africanidade. Pode-se praticar os usos e costumes africanos sem por isso ser afrocêntricos. Afrocentricidade é a conscientização sobre a agência dos povos africanos. Essa é a chave para reorientação e recentralização, do modo que a pessoa possa atuar como agente, e não como vítima ou dependente (ASANTE 2009, p. 94).

Portanto, podemos perceber que uma pessoa possa ter costumes africanos e se apropriar das tradições culturais das histórias da cultura africana e afro-brasileira, mas ainda assim, não ser um ser afrocêntricos por não ter consciência política sobre a as verdadeiras histórias dos povos negros se expressando apenas quando for conveniente sem a devida consciência.

Dando continuidade as categorias propostas pela teoria da afrocentricidade, abaixo iremos conhecer o conceito de agente e agência, sendo esses dois termos de fundamental importância para o fortalecimento da teoria que segundo Asante (2009):

Um agente, em nossos termos, é um ser humano capaz de agir de forma independente em função de seus interesses. Já a agência é a capacidade de dispor dos recursos psicológicos e culturais necessários para o avanço da liberdade humana. Em uma situação de falta de liberdade, opressão e repreensão racial, a ideia ativa no interior do conceito do agente assume posição de destaque. (ASANTE, 2009, p. 95).

Vejamos então, a diferença entre agente e agência de forma afrocentrada, conforme o autor, sendo a pessoa um "agente", ela tem a capacidade de agir de acordo com seus próprios interesses. Já a "agência" e a capacidade dos seres humanos em dispor de recursos psicológico e culturais para o avanço da libertação humana.

Valores afro no centro do discurso e também com o lugar de fala. Afrocentrar os processos educativos é colocar a África no centro das ações. África no centro não apenas no sentido de continente estático limitado à sua localização geográfica, mas, considerando sua influência cultural e também a diáspora do povo africano. Assim, devemos considerar a população que foi sequestrada e trazida para as Américas e demais localidades do globo 
terrestre. Desta forma, a afrocentricidade considera cada indivíduo de origem e/ou descendência africana como africano em diáspora. A partir da teoria afrocentrada identificamos as categorias do paradigma afrocentrado é caro ao debate acerca da educação. Para Asante, o processo de colonização impeliu os sujeitos africanos do continente ou em diáspora a serem descentrados pela perspectiva eurocêntrica. Pois, além do processo escravizador que sofreram os povos africanos, contamos também com séculos de expropriação das riquezas deste continente somados também à subalternização de seu legado cultural. Assim, sobre a África historicamente foi construída ou atribuída um lugar de produção histórica/cultural minoritária em relação ao padrão eurocentrista adotado como superior e hegemônico.

\section{Percurso metodológico}

Metodologia é o caminho que percorremos durante todo o nosso processo de análise do Projeto "O BAOBÁ, ÁRVORE QUE REPRESENTA AS RAÍZES DA CULTURA AFRICANA". A presente pesquisa é um estudo de caso e teve como instrumento da coleta de dados a análise do projeto escrito. Os sujeitos da pesquisa são os envolvidos no processo de confecção do projeto, bem como, alunos que participaram das atividades. O Campo de Pesquisa é a Escola Albenice Maria da Silva Jaboatão-PE.

Optamos pela análise do conteúdo dos objetivos do projeto. Entendemos que este documento nos mostra a possibilidade de chegarmos ao ponto que desejamos que é identificar proposições de processos pedagógicos que se voltem e/ou se afastem de uma perspectiva de educação afrocentrada.

Para isso, o primeiro momento da pesquisa foi o de caracterizar o local específico onde a pesquisa foi desenvolvida. Sendo assim, caracterizamos a escola e também o projeto do fórum. Outro detalhe é que entendemos que uma pesquisa com essas características não pode ser contemplados apenas através de estatísticas. Nesse sentido, aqui se justifica uma abordagem qualitativa porque, segundo Minayo

responde a questões muito particulares. Ela se preocupa [...] com um nível de realidade que não pode ser quantificado. Ou seja, ela trabalha com o universo de significados, motivos, aspirações, crenças, valores e atitudes, o que corresponde a um espaço mais profundo das relações, dos processos e dos fenômenos que não podem ser reduzidos à operacionalização de variáveis (1999, p. 24). 
Assim sendo, analisamos desenvolvemos uma análise do conteúdo dos objetivos do fórum. Para Bardin (2010), a referida análise do conteúdo pode ocorrer a partir de três momentos, sendo eles: Pré-análise(coleta de dados); Exploração do material e Tratamento dos resultados obtidos e interpretação.

$\mathrm{Na}$ Pré-análise desenvolvemos uma leitura de todo o projeto aqui estudado e identificamos que a partir dos objetivos(geral e específicos) poderíamos compor a nossa análise.

No segundo momento desenvolvemos a exploração do material. Neste momento decidimos adotar por utilizar como categorias de análise os princípios da afrocentricidade. Sendo assim, buscamos no texto dos objetivos proposições que apontassem a Localização, Conscientização, Agente e Agência. Assim, de acordo com o contexto analisamos a aproximação da educação afrocentrada e/ou o afastamento.

A interpretação dos resultados obtidos pode ser feita por meio das inferências, que é um tipo de interpretação controlada e fundamentada teoricamente. Segundo Bardin (2010, p. 41) é a "operação lógica, pela qual se admite uma proposição em virtude da sua ligação com outras proposições já aceitas como verdadeiras". Consideramos aqui a teoria de Asante (2009).

\section{Resultados e discussões}

Ao analisar nos objetivos do projeto princípios da afrocentricidade encontramos os resultados seguintes: O Objetivo Geral do fórum escolar de consciência negra foi o de,

Valorizar a cultura afro-descendente presente na Brasil, bem como seus costumes, valores, lutas e ensinamentos transmitidos a sociedade tendo como alicerce o BAOBÁ, árvore símbolo fundamental das culturas Africanas.

Aqui, no objetivo geral, consideramos a categoria Localização afrocentrada podemos incluir um posicionamento que esteja alicerçado nas experiências históricas desta etnia. Desta forma, ao problematizar costumes, valores, lutas e ensinamentos afro transmitidos a sociedade podemos considerar não apenas o olhar eurocêntrico, mas, ressaltar o olhar africano e valorizar todo o seu legado presente na cultura brasileira. Desta forma, compreendemos que

Dentro do paradigma afrocentrado, localizar diz respeito à demarcação e destaca as referências africanas como centro. Em outros termos, na configuração de africanidades enquanto 
topologicas epistêmicas, isto é, partir de "lugares" africanos. O que se traduz no campo da educação através da ênfase no ponto de vista que situa os povos africanos e a população afrodescendente como agentes e não coadjuvantes. (NOGUEIRA,2010, p. 03-04)

Assim sendo, colocar o Baobá no centro da atividade como tema gerador colocamos uma referência africana na base da discussão. Acreditamos que localizar essa representação pode despertar o empoderamento afro nos atores envolvidos no processo (os alunos/as e professores/as). O Baobá é uma parte da África que está em diáspora e agora está literalmente presente no espaço da escola.

Os Objetivos Específicos do fórum foram os seguintes,

Reconhecer a importância e a contribuição da cultura africana como fonte de conhecimento e aprendizagem que perpassaram a formação da cultura brasileira; Valorizar a cultura negra e seus afro-descendentes e afro-brasileiros, na escola e na sociedade; Valorizar a identidade do(a) adolescente negro(a); Desmitificar o preconceito relativo aos costumes religiosos provindos da cultura africana; Realizar discussões provocantes, por meio das rodas de conversa, sobre o preconceito sofrido pelos afro-descendentes em nossa sociedade, para um posicionamento mais crítico frente à realidade social em que vivemos; Refletir sobre o legado da cultura negra através da música, da alimentação, dos usos e costumes; Reconhecer a história, lendas e crendices religiosas em torno do Baobá, bem como sua importância cultural para os africanos e seu descendentes; Oportunizar, através do resgate cultural e apresentações artísticas, aos participantes o estímulo à pesquisa; e Fomentar o pertencimento étnico e a cultura.

Ao reconhecer a importância e a contribuição da população africana e afrodescendente localizada a partir de seu próprio ponto e vista nos revela a categoria Agência que abrange "a capacidade de dispor dos recursos psicológicos e culturais necessários para o avanço da liberdade humana." (ASANTE, 2009, p.94). No paradigma afrocentrado entendemos Agência como o conjunto de dispositivos e sua devida articulação em prol da questões afro. Nesta perspectiva, o conceito de Agência constrói um embate à estrutura pré-estabelecida, pois, nós negros não precisamos nos render nem nos calar, mas sim sermos Agência e ter o lugar de fala. Desta forma, entendemos que as ações educativas do projeto visaram contemplar a agência da Lei 10.639/2003. A lei foi estabelecida e sancionada por decreto Nacional tem por objetivo construir a obrigatoriedade do ensino sobre a história e cultura afro-brasileira nos níveis fundamental e médio das redes de ensino nacionais, pública e privadas. Esta Lei altera a Lei 9.394/96, que estabelece as diretrizes e bases da educação brasileira (LDB),

$\begin{array}{ll}\text { REVISTA } & \text { Interritórios | Revista de Educação } \\ \text { interritórios } & \text { Universidade Federal de Pernambuco, } \\ \text { Caruaru, BRASIL | V.6 N.12 [2020] }\end{array}$


incluindo no currículo oficial a obrigatoriedade dos assuntos de História e Cultura Afro-Brasileira em toda Rede de ensino nacional.

Quanto à conscientização, de modo geral entendemos como o ato de estar consciente, o projeto buscou um posicionamento mais crítico frente à realidade social em que vivemos. Para Freire (1996, p.09), "a conscientização é exigência humana, é um dos caminhos para a posta em prática da curiosidade epistemológica. Em lugar de estranha, a conscientização é natural ao ser que, inacabado, se sabe inacabado.”. Na afrocentricidade a categoria Conscientização é o que orienta os seres humanos no conhecimento sobre as diversas formas de opressões que são submetidos e, além disso, é o que orienta as vias possíveis para a libertação. Desta forma, identificamos que ao Fomentar o pertencimento étnico as estratégias pedagógicas visam estimular que os educandos pudessem sair da condição de des agência para a condição de agente.

Identificamos que os processos pedagógicos propostos nos objetivos do projeto não se distanciaram de uma perspectiva afrocentrada de educação.

\section{CONCLUSÕES}

Concluímos que surgem mais e mais esforços de atividades que se alinhem a uma proposta afrocentrada de educação. Sabendo que, a sociedade brasileira se estruturou em um paradigma eurocêntrico, brancocentrico e racista.

Considerando o foco desse estudo, que foi o de verificar os processos pedagógicos escolares como fortalecimento da afrocentricidade no combate ao racismo no ambiente escolar. Acreditamos que os esforços do projeto se aproximaram e se alinham a uma proposta afrocentrada de educação.

Também acreditamos que o presente estudo abre a possibilidade para demais estudos futuros que possam desenvolver uma análise da atividade a partir de outros aspectos como entrevistas com os atores identificando memórias e narrativas da atividade. Entre outras possibilidades que visem tratar o objeto com outros possíveis lócus de observação.

Ressaltamos a presença dos princípios da afrocentricidade dentro dos objetivos do projeto os quais contemplaram a Localização, Conscientização, Agente e Agência. Nesse estudo identificamos os esforços para a sensibilização de estudantes acerca dos valores humanos e de processos pedagógicos que ultrapassem as fronteiras do racismo, da discriminação e da violência dentro e fora dos muros da escola.

\section{REFERÊNCIAS}


ASANTE, Molefi Kete. Afrocentricidade: uma abordagem epistemológica inovadora (Coleção Sankofa — Livro 4) organizado por Elisa Larkin. Editora Selo Negro, 2009.

BARDIN, Laurence. Análise de conteúdo. Lisboa: Edições 70, 2010.

FREIRE, Paulo. Pedagogia da autonomia: saberes necessários à prática educativa. - São Paulo: Paz e Terra, 1996;

MINAYO, M. C. S. (Org.). Pesquisa social: teoria, método e criatividade. 13. ed. Petrópolis: Vozes, 1999.

NOGUEIRA, Renato dos Santos Junior. Afrocentricidade e educação: os princípios gerais para um currículo afrocentrado. Revista África e Africanidades, 2010.

SANTOS, Rayane Pereira; RODRIGUES, Ana Cláudia da Silva. Currículo contextualizado em escolas do campo: relatos de uma experiência. Revista Interritórios. Recife-PE, 2019.

<http://www.planalto.gov.br/ccivil_03/LEIS/2003/L10.693.htm> Acesso em 16 de agosto de 2020 às 5 h.

$<$ https://cidades.ibge.gov.br/brasil/pe/jaboatao-dos-guararapes> Acesso em 16 de agosto de 2020 às 5 h30. 